\section{Direct PCR of Symbiotic Fungi Using Microslides}

BioTechniques 26:454-455 (March 1999)

Successful DNA isolation is a critical step in molecular studies of symbiotic fungi including plant pathogens, mycorrhizal fungi, endophytic fungi and lichen-forming fungi. Whereas standard isolation protocols are usually the straightforward approach if axenic cultures are available, it is problematic to isolate DNA from fungi that grow in intricate associations with some other organisms. If the symbionts cannot be separated and the isolate contains DNA of different sources, discriminative primers are used during polymerase chain reaction (PCR) to obtain products from the organisms of interest. For example, studies of nuclear small subunit ribosomal (r)DNA from lichen-forming ascomycetes rely on primers that do not amplify the algal symbiont $(2,3)$. Such primers still have to be developed for other genes, and if two closely related fungi occur together, the design of specific primers might be difficult. One strategy in such cases is the careful preparation of small amounts of homogeneous starting material. There are spectacular reports on DNA amplification from single spores (6), but our experience is that this procedure has failed with a variety of organisms, particularly lichens. Previously, a special protocol had been developed for DNA isolation from lichen fruitbodies (4). However, using very small amounts of lichens as starting material can be cumbersome because this includes an increased risk of obtaining odd amplification results due to contaminating organisms. Therefore, it would be ideal to check the material for contaminants under a microscope before PCR.

Here, we describe an alternative approach that we often used successfully to amplify DNA from symbiotic fungi. Sections of the organisms were mounted on small glass splinters, and PCR was carried out with fungal-specific primers with this material without previous DNA isolation. Earlier, direct PCR using sections had been carried out with standard microscopic slides (8). In addition to the handling problems that occur when a large number of samples are processed, these techniques require considerable space on a thermal cycler, whereas amplification in our protocol is carried out in tubes conventionally used for PCR. This is possible by using $2-\times 10$-mm large glass slides (or microslides) (5) that were cut from standard coverslips using a diamond cutter. The glass slides were washed in sterile water, $2 \times$ for $5 \mathrm{~min}$ in $100 \% \mathrm{EtOH}$, air-dried and immersed in a gelatin/chromalum solution $(0.25 \%$ gelatin, $0.025 \%$ chromium III potassium sulphate) for $5 \mathrm{~s}$ under sterile conditions. Then, the coated microslides were dried on an aluminum foil.

To test whether it is possible to selectively amplify material of co-existing fungi, we used a lichen that was infected by another fungus. The parasite Arthonia molendoi develops black fertile structures in the orange, disc-like fruitbodies of its host lichen Xanthoria elegans. An infected fruitbody of Xanthoria was carefully oriented for cryo- sectioning $\left(-15^{\circ} \mathrm{C}\right.$ knife temperature; Cryostat; Leitz, Wetzlar, Germany) to obtain a series of parallel, horizontal sections from the apex of the black lichenicolous fruitbody downwards into the infected host. The first few sections with larger amounts of dark pigmented layers of the lichenicolous fruitbodies were discarded. Several sections of 4$\mu \mathrm{m}$ thickness measured $60 \times 60$ to $750 \times$ $550 \mu \mathrm{m}$. In the first of these sections, no material from the host lichen was apparent, whereas subsequent sections contained increasing amounts of material from the host. Each section was placed close to the very bottom of a separate, coated glass slide, which was handled with sterile forceps. The microslides with attached sections were then collected in a Petri dish and dried for $5 \mathrm{~min}$ at $45^{\circ} \mathrm{C}$ in an oven. After drying, the slides were microwaved for $10 \mathrm{~min}$ in a conventional microwave oven $(800 \mathrm{~W}$ maximal power output with $2450 \mathrm{mHz}$ operating frequency), which enhanced the attachment to the slides. A half-closed $500-\mathrm{mL}$ bottle containing $150 \mathrm{~mL}$ dis-

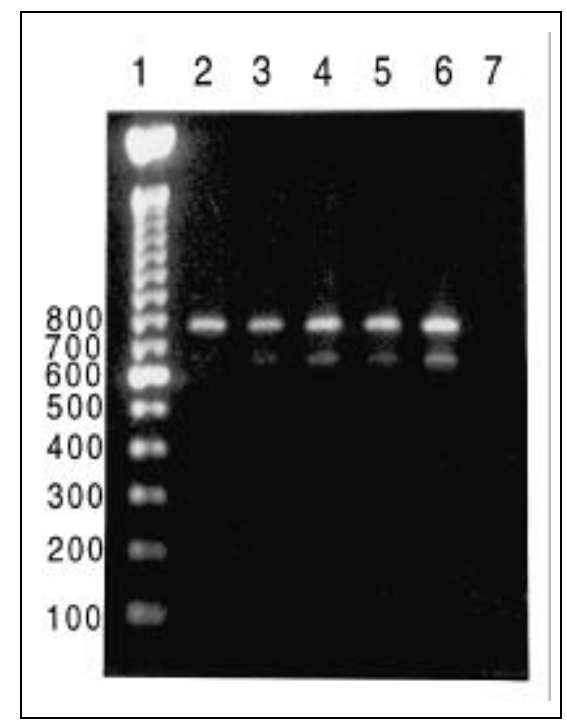

Figure 1. PCR products obtained from cryosections of symbiotic fungi. A series of tangential sections was prepared from a $X$. elegans fruitbody infected by $A$. molendoi and used directly for PCR amplification. Lane 1: 100-bp ladder size marker. Lane 2: PCR product of $790 \mathrm{bp}$ from A. molendoi obtained from a section without visible material from the host lichen. Lanes 3-5 include products from the parasite and the host in the sections. The product from the host differs in size $(650 \mathrm{bp})$. Lane 6: products from the parasite and the host are present, but no infection symptoms were detected under the microscope. Lane 7: slide without fungal material as a control. 
tilled water was present in the heating chamber to avoid destruction of the oven. Then, the sections were examined microscopically for contaminations, and parts with crystallized secondary products of the host lichen were removed by microdissection using an acid-washed and sterilized glass needle. Afterwards, each microslide was placed in a separate 0.5-mL microcentrifuge tube containing $15 \mu \mathrm{L}$ amplification mixture (DynaZyme $^{\mathrm{TM}}$; Finnzymes Oy, Espoo-Esbo, Finland) according to the manufacturers' specifications. The mixture was covered with mineral oil. After a 5-min initial denaturation at $94^{\circ} \mathrm{C}$, all samples were then amplified in a single run of 30 cycles on a DNA Thermal Cycler 480 (Perkin-Elmer, Norwalk, CT, USA) with the following reaction conditions: $60 \mathrm{~s}$ at $94^{\circ} \mathrm{C}, 45 \mathrm{~s}$ at $52^{\circ} \mathrm{C}$ and $90 \mathrm{~s}$ at $72^{\circ} \mathrm{C}$. Primers used were ITS1F ( $5^{\prime}$-CTTGGTCATTTAGAGGAAGTAA-3') (1) and ITS4 (5'-TCCTCCGCTTATTGATATGC-3') (7). All experiments included one blank microslide as a negative control. The amplified products were run on an $1 \%$ agarose gel and visualized by ethidium bromide staining.

The direct PCR from an apical section showed only a single PCR product from A. molendoi. As confirmed by light microscopy, this section did not contain any visible fertile tissue of $X$. elegans. All other sections revealed two bands that differed significantly in sequence (unpublished data). The increasing concentration of a shorter product (Figure 1) correlated with an increasing amount of tissue from the host lichen. Even if symptoms of infection were not apparent under the microscope in basal sections, the presence of the longer PCR product clearly indicated the presence of the parasitic hyphae. Further experiments are required to show whether the infection can be detected in all parts of the lichen. With this example, we show that our method is useful to investigate symbiotic fungi and their distribution in host organisms in greater detail and to obtain PCR products from low amounts of homogeneous starting material.

One further advantage of this technique is that sections attached to microslides are easily handled. This facilitates the removal of undesired parts by microdissection under a microscope or allows subsequent PCR experiments. Furthermore, relatively low amounts of amplification mixture is required, and a larger number of samples can be processed in a conventional thermocycler.

\section{REFERENCES}

1.Gardes, M. and T.D. Bruns. 1993. ITS primers with enhanced specificity for Basidiomycetes. Application to the identification of mycorrhizae and rusts. Mol. Ecol. 2:113-118.

2.Gargas, A. and P.T. DePriest. 1996. A nomenclature for fungal PCR primers with examples from intron-containing SSU rDNA. Mycologia 88:745-748.

3.Gargas, A. and J. Taylor. 1992. Polymerase chain reaction (PCR) primers for amplifying and sequencing nuclear 18S rDNA from lichenized fungi. Mycologia 84:589-592.

4.Grube, M., A. Gargas, P.T. DePriest and J. Hafellner. 1995. DNA isolation from lichen ascomata. Mycol. Res. 99:1321-1324.

5.Hindkjaer, J., C. Terkelsen, S. Kølvraa, J. Koch and L. Bolund. 1996. Detection of nucleic acids (DNA and RNA) in situ by single and cyclic primed in situ labelling (PRINS): two alternatives to traditional in situ hybridization methods, p. 45-66. In M. Clark (Ed.), In Situ Hybridization. Chapman and Hall, London.

6.Lee, S.B. and J.W. Taylor. 1990. Isolation of DNA from fungal mycelia and single spores, p. 282-287. In M.A. Innis, D.H. Gelfand, J.J. Sninsky and T.J. White (Eds.), PCR Protocols: A Guide to Methods and Applications. Academic Press, San Diego.

7.White, T.J., T. Bruns, S. Lee and J. Taylor. 1990. Amplification and direct sequencing of fungal ribosomal RNA genes for phylogenetics, p. 315-322. In M.A. Innis, D.H. Gelfand, J.J. Sninsky and T.J. White (Eds.), PCR Protocols: A Guide to Methods and Applications. Academic Press, San Diego.

8.Yap, E.P.H. and J.O'D. McGee. 1991. Slide PCR: DNA amplification from cell samples on microscopic glass slides. Nucleic Acids Res. 19:4294.

This work was partly supported by Austrian Science Foundation (FWF) Grant No. P11998-Gen. Address correspondence to Dr. Martin Grube, Karl-Franzens-Universität Graz, Institut für Botanik, Holteigasse 6, A-8010 Graz, Austria. Internet: martin. grube@kfunigraz.ac.at

Received 30 October 1998; accepted 28 December 1998.

Heimo Wolinski, Martin Grube and Paul Blanz Karl-Franzens-Universität Graz Graz, Austria 